\title{
Determination of Fuel Properties of Biodiesel from Sand Apple Seed Oil with Automotive Gas Oil Blend
}

\author{
1ADEYEMI, DT; *2SALEH, A; ${ }^{3}$ AKANDE, FB; ${ }^{3}$ ONIYA, OO; ${ }^{3} \mathrm{OLA}$, FA \\ ${ }^{1}$ National Centre for Agricultural Mechanization, Ilorin, Kwara State, Nigeria \\ ${ }^{2}$ Department of Agricultural and Bio-Resources Engineering, Ahmadu Bello University, P.M.B. 1044, Zaria, Nigeria \\ ${ }^{3}$ Department of Agricultural Engineering, Ladoke Akintola University of Technology, Ogbomoso, Nigeria \\ *Corresponding Author, Email: salehaminu@gmail.com; Tel: +23480 3574780
}

\begin{abstract}
The objective of this study was to determine the fuel properties of Sand Apple Ethyl Ester (SAEE) and its blends with Automotive Gas Oil (AGO).using eggshell as catalyst. Sand apple seed oil (SASO) obtained was characterized based on America Society for Testing and Material (ASTM D6751) to determine acid value, saponification, iodine content, density, kinematic viscosity, flash point, cloud point and pour point. Sand Apple fruits were processed and oil extracted using solvent extraction method. Raw eggshells were calcined at $800^{\circ} \mathrm{C}$ for $120 \mathrm{~min}$ in the muffle furnace. SAEE was blended with AGO at $5-25 \%$ mix. Data obtained was analyzed using ANOVA at P 0.05 significant level. Cloud and pour points obtained for SASO are 4.68 and $3.09^{\circ} \mathrm{C}$. Flash point was $103^{\circ} \mathrm{C}$ which fell within ASTM D93 range indicating that SASO is safe for handling and storage. Heating value was $42.61 \mathrm{MJ} / \mathrm{kg}$, slightly lower than that of diesel oil of $44.8 \mathrm{MJ} / \mathrm{kg}$ shows that AGO has ability to produce heat of combustion than SASO. Iodine value was $80.71 \mathrm{~g} \mathrm{I} / 100 \mathrm{~g}$ while acid value was determined to be $2.62 \mathrm{mgKOH} / \mathrm{g}$, which was higher than that of ASTM D6751 of $0.5 \mathrm{mgKOH} / \mathrm{g}$. Sulphur contents for AGO and SASO-AGO blends were 0.006, 0.009, 0.014, 0.016 and 0.004\%, respectively. Low sulphur values indicates that hazardous sulphur dioxide emission of SAEE has reduced. This study established that all the properties obtained, except acid value, fell within the ASTM specification and could suitably be compared with those of fossil diesel.
\end{abstract}

DOI: https://dx.doi.org/10.4314/jasem.v25i8.12

Copyright: Copyright (C) 2021 Adeyemi et al. This is an open access article distributed under the Creative Commons Attribution License (CCL), which permits unrestricted use, distribution, and reproduction in any medium, provided the original work is properly cited.

Dates: Received: 10 May 2021; Revised: 28 June 2021; Accepted: 01 July 2021

Keywords: Biodiesel, Sand Apple, Properties, Ethyl Esters, Blend

The demand for crude petroleum oil in the world constantly increase to about 75 million barrels per day. This translates to about $7 \%$ annual increase (OPEC, 2009). Similarly, continuous increase in price and consumption of petroleum products coupled with political and social instability in developing countries, particularly in Nigeria, have created the need to produce alternative fuels that are renewable and have positive environmental benefit (Barnwal and Sharma, 2005). Dependence on these fossil fuels has led to an increase in environmental pollution and global warming. Recent researches on bio-renewable fuels were mostly focused on producing biodiesel from vegetable oils as an alternative fuel for diesel engine. More attention have to be paid on non-edible oil seeds such as SASO grown in tropical and subtropical regions across the underdeveloped countries (Oyelade et al., 2017; Odetoye et al., 2014; Bamgboye and Oniya, 2012). Sand apple belongs to the family of rosaceae that is found in tropical savannah region of West Africa. It is common in North-Central region and some parts of Southern states of Nigeria where it has been grossly underutilized either because of its non-edibility and lack of extensive research on it. Biofuels have been reported to be suitable for alkyd resin production with desirable properties (Odetoye $e t$ al., 2014). These properties include acid value, saponification value, iodine value, density, viscosity, flash and cloud points of the oil. However, combustion of biofuels results in deposits formation which include carbon monoxides, surphur dioxide, volatile organic compound, and heavy metal that are harmful to human health and the environment (Gerpen, 2005). The properties have also been noted with serious effects to the engine by causing engine delay, deposit and particulate matter that led to poor engine performance. There is therefore a need to explore and investigate such properties for Sand Apple in order to determine its suitability for use in Internal Combustion Engines, hence the objective of this study.

\section{MATERIALS AND METHODS}

SASO was extracted from sand apple seeds (SASs) in the Mechanical Engineering Laboratory of Ladoke Akintola University of Technology, Ogbomoso via solvent extraction method. Materials are $50 \mathrm{ml}$ 
beakers, $5 \mathrm{ml}$ conical flasks, pipette, Cannon Fensky capillary viscometer, stop watch, electric weighing balance, pyrometer, thermometer, cooling bath, Gallen Kamp Ballistic bomb calorimeter, $25 \mathrm{ml}$ of diethyl ester and $25 \mathrm{ml}$ of ethanol, measuring cylinder and potassium hydroxide.

Characterization of sand apple seed oil (SASO): The sand apple oil obtained was characterized based on America Society for Testing and Material (ASTM D6751) to determine acid value, saponification value, iodine value, density, kinematic viscosity, flash point, cloud point and pour point of the oil as recommended by Oniya (2010); Abdul Rohman et al., (2015) and various ASTM standards.

Determination of acid value: A $25 \mathrm{ml}$ of diethyl ester and $25 \mathrm{ml}$ of ethanol were mixed in a beaker. This was added to $5 \mathrm{~g}$ of biodiesel in a conical flask. A drop of phenolphthalein as indicator was added to the mixture and shaken vigorously. Acid value was calculated as the percentage of acid present by stating the result in terms of oleic acid. Acid value was determined from Equation 1.

$$
A_{v}=14.1 \times \frac{V_{o}}{W_{O}}
$$

Where: $A_{v}=$ Acid value; $V_{O}=$ Volume of $0.5 \mathrm{M}$ $\mathrm{NaOH}(\mathrm{ml}) ; W_{O}=$ sample weight, $(\mathrm{g})$

Determination of saponification value: The saponification value was determined by completely saponifying the oil. One gram $(1 \mathrm{~g})$ of the oil sample was transferred into a flask and adds $10 \mathrm{~cm}^{3}$ of $0.5 \mathrm{M}$ $\mathrm{KOH}$ and $5 \mathrm{~m}^{3}$ of ethanol. Another flask was added with $20 \mathrm{~cm}^{3}$ of $0.5 \mathrm{M} \mathrm{KOH}$ without oil and used for blank determination. The two flasks were fitted with air condenser and reflux the contents on a water bath for $1 \mathrm{hr}$. The contents was cooled slightly, disconnected the condenser and rinse with distilled water. 10 to 13 drops of phenolphthalein were added to the contents of the two flasks and titrated with standard solution of $0.5 \mathrm{M}$ hydrochloride $\mathrm{HCl}$. The saponification value was determined from Equation 2.

$$
S_{v}=\frac{(B-A)}{W} \times 28
$$

Where: $S_{v}=$ Saponification value; $B=$ volume of 0.5 $\mathrm{M} \mathrm{HCl}$ used for blank, $(\mathrm{ml}) ; A=$ volume of $0.5 \mathrm{M}$ of $\mathrm{KOH}$ used for sample, $(\mathrm{ml}) ; W=$ weight of oil sample, (g)

Determination of iodine value: Iodine value was determined according to ISO 3761 (2005). $1 \mathrm{~g}$ of the biodiesel was poured into a conical flask and $10 \mathrm{ml}$ of carbon tetrachloride was added to it. A $25 \mathrm{ml}$ of Dam reagent was then added to the content in the flask using safety pipette in the fume chamber and mixed vigorously. The flask was placed in the dark for $2 \mathrm{~h} 30$ min. At the end of this period, a $20 \mathrm{ml}$ of $10 \%$ aqueous Potassium Iodide and $125 \mathrm{ml}$ of water were added to the mixture. The whole content was treated with $0.1 \mathrm{M}$ sodium-thiosulphate solution until the yellow colour almost disappeared. A drop of $1 \%$ of starch indicator was added to the content in the flask and titrations continue with sodium-thiosulphate, until colour of the content turns blue. The same procedure was used for blank test without biodiesel. The iodine value biodiesel was determined by the expression in Equation 3.

$$
I_{v}=\frac{12.69 \times C\left(V_{1}\right)-\left(V_{2}\right)}{M}
$$

Where: $I_{v}=$ Iodine value; $C=$ concentration of sodium thiosulphate used $(\mathrm{g} / \mathrm{ml}) ; V_{l}=$ Volume of sodium thiosulphate used for blank $(\mathrm{ml}) ; V_{2}=$ volume of sodium thiosulphate used for determination $(\mathrm{ml}) ; M$ $=$ mass of the sample $(\mathrm{g})$

Determination of kinematic viscosity: Kinematic viscosity of fuel sample was determined using Cannon Fensky capillary viscometer tube calibrated series obtained from Central Research and Diagnostic Laboratory, Tanke, Ilorin according to ASTM D445/446, (2017). The process was conducted by measuring the time required for a volume of fuel sample to flow by gravity through capillary of the viscometer. The fuel sample was poured into viscometer which was held vertically at room temperature of $28{ }^{\circ} \mathrm{C}$ and allowed to move to the upper meniscus. A stop watch was preset to know the time taken from upper meniscus to lower meniscus. The same process was repeated at temperature of $40^{\circ} \mathrm{C}$ three times and average value was obtained. Value obtained was then multiplied by the factor or path length of the viscometer. The viscosity $\mathrm{V}$ in $\mathrm{m}^{2} / \mathrm{s}$ was calculated from Equation 4.

$$
V_{k}=k t
$$

Where: $V_{k}=$ Viscosity $\left(\mathrm{m}^{2} / \mathrm{s}\right) ; k=$ the constant calibration of the viscosity $\left(\mathrm{m}^{2} / \mathrm{s}^{2}\right) ; t=$ time (s)

Determination of specific gravity: The specific gravity of the fuel sample was determined according to ASTM D1298, (2005) method using empty pyrometer weighed with electric weighing balance and denoted as $W_{1}$. A required fuel sample at $15^{\circ} \mathrm{C}$ was poured into pyrometer and weighed as $W_{2}$. An equal volume of distilled water was weighed and denoted Ww. The 
specific gravity (SG) of fuel sample was calculated as in equation 5 .

$$
S . G=\frac{W_{2}-W_{1}}{W_{w}-W_{1}}
$$

Where: $W_{1}=$ weight of empty pycometer $(\mathrm{g}) ; W_{2}=$ weight of pycometer fuel sample $(\mathrm{g}) ; W_{w}=$ weight of equal volume of distilled water $(\mathrm{g})$

Determination of flash point: The flash point was determined at the minimum temperature in which the vapour evaporated by the fuel samples when a test flame was held above the surface without the fuel catching the fire. Refusina Penky Martem flash point closed cup apparatus was obtained at Lubcon Oil Company, Ilorin, Nigeria. The test was conducted according to ASTM D93, (2018) method where a brass test cup fitted with cover was filled with sample. The sample was heated and stirred in a container. An ignition source was directed into the cup at regular increment of $2^{\circ} \mathrm{C}$ with simultaneous interruption of stirring until a flash that spread throughout the inside of the cup is seen; the corresponding temperature at this point is known as flash point.

Determination of sulphur content: Sulphur content of the sand apple oil produced was determined by the ASTM standard. Oil sample was poured into a high temperature combustion tube where sulphur is oxidized to sulphur dioxide $\left(\mathrm{SO}_{2}\right)$ in an oxygen rich atmosphere. Oil combustion gases were then exposed to ultraviolet rays. The $\mathrm{SO}_{2}$ was then excited from which fluorescence was emitted as it returns to its stable state. The fluorescence detected by a photomultiplier tube and the signal was a measure of the amount of sulphur contained in this oil (ASTM, D6751, 2002).

Determination of carbon content: Carbon content of the sand apple oil was determined by ASTM method using Conrad son residue that was specified by heating the product in a standard crucible with a burner, in such a way that the vapours which are freed were burned up within a specified time (ASTM D5291, 2018).

Determination of heating value: The heating value of fuel samples was determined according to ASTM D40, (2005). Gallen Kamp Ballistic bomb calorimeter was used to determine the heating or calorific value of the fuel. A required amount of fuel sample was burnt in a bomb calorimeter. Air in the system was replaced by pure oxygen. A maximum deflection of the galvanometer on the control box was recorded after using the samples. The effective heat capacity of the system was also determined using the same procedure but with pure and dry benzoic acid as the test fuel. The heating value was calculated using Equation 6:

$$
H . V=\frac{Y\left(a_{3}-a_{1}\right)}{Z}
$$

Where; $H . V=$ Heating Value; $a_{1}=$ Galvanometer deflection without sample; $a_{3}=$ Galvanometer deflection with sample; $Y=$ Calibration constant; $Z=$ mass of fuel sample $(\mathrm{g})$

The calibration constant $(\mathrm{Y})$ is given by Equation 7:

$$
Y=\frac{6.32 w_{1}}{a_{2}-a_{1}}
$$

Where; $Y=$ Constant; $a_{1}=$ Galvanometer deflection without sample; $a_{2}=$ Galvanometer deflection with benzoic sample; $w_{1}=$ mass of benzoic acid $(\mathrm{g})$

Determination of cloud point: Cloud point of SASO was determined according to ASTM D2500 (2015). The fuel sample was first poured into a test jar to a level approximately half full. A cork carrying the test thermometer was used as closed jar. The thermometer bulb was positioned to rest at the bottom of the jar. The whole test then placed in a constant temperature cooling bath on top of a gasket to prevent excessive cooling. At every $1^{\circ} \mathrm{C}$, the sample was taken out and inspected for cloud then quickly replaced until crystal appears as cloud using visual inspection in the clear fuel sample as cloud point.

Determination of pour point: Pour point of the sample is the temperature below which the liquid loses its flowing characteristics. It was determined according to ASTM D97 (2005) method where the fuel was cooled inside a cooling bath to allow the formation of crystal. At about $9^{\circ} \mathrm{C}$ above expected point, the test jar was removed and tilted for $5 \mathrm{sec}$. to check for surface movements. Fuel sample was observed at $3^{\circ} \mathrm{C}$ intervals to flow. The lowest temperature at which the sample moves was noted as the pour point.

\section{RESULTS AND DISCUSSION}

The properties of SASO were determined according to various recommendation stated. Inferences were also made with that of ASTM standards. Results of the study were presented in Tables 1.

Table 1: Physiochemical properties of sand apple and ASTM/EN

\begin{tabular}{lll} 
& oil & \\
\hline Properties & Sand apple oil & ASTM/EN \\
\hline Iodine value $(\mathrm{gI} / 100 \mathrm{~g}$ oil $)$ & 80.71 & 120 \\
Acid value $(\mathrm{mgKOH} / \mathrm{g})$ & 2.62 & 0.5 \\
\hline
\end{tabular}




\begin{tabular}{lll}
\hline Specific gravity & 0.83 & 0.98 \\
Viscosity @ $40{ }^{\circ} \mathrm{C}\left(\mathrm{mm}^{2} / \mathrm{s}\right)$ & 4.2 & $1.9-6.0$ \\
Flash point $\left({ }^{\circ} \mathrm{C}\right)$ & 103 & 93 \\
Cloud point $\left({ }^{\circ} \mathrm{C}\right)$ & 4.68 & 4.00 \\
Pour point $\left({ }^{\circ} \mathrm{C}\right)$ & 3.09 & 8.00 \\
Heating value $(\mathrm{MJ} / \mathrm{kg})$ & 42.61 & 39.62 \\
\hline
\end{tabular}

From the results obtained, iodine value of SASO was found to be $80.71 \mathrm{gI} / 100 \mathrm{~g}$ compared to EN14214, (ISO 3761, 2005) standard oil which was $120 \mathrm{~g} \mathrm{I} / 100 \mathrm{~g}$. It was observed that iodine value was higher than that of SASO indicating that it has higher unsaturated fat than SASO. The acid value of SASO was determined to be $2.62 \mathrm{mgKOH} / \mathrm{g}$, which was higher than that of ASTM D6751, (2018) of $0.5 \mathrm{mgKOH} / \mathrm{g}$. this result indicates the mass of potassium hydroxide, that is required to neutralize $1 \mathrm{~g}$ of the fuel substance and is useful in determining the number of carboxylic acid functional groups on a molecule. Acid value is measured by dissolving a known amount of fuel in an organic solvent and titrating it with a solution of known concentration of $\mathrm{KOH}$ with phenolphthalein indicator. The higher acid value of SASO indicated that SASO could be more corrosive to engine parts than that of ASTM D 6751, (2018) oil. However, ASTM standard has more suitability for lubrication under operating condition of engine than SASO oil but SASO could equally be treated to reduce the acidic value to make it suitable for engine operation. The specific gravity of sand apple oil was 0.836 as presented in Table 1. This value shows that their fluids characteristic are comparable and fell within the ASTM D792, (2015) standard. Results from similar studies showed that the specific gravity values of sunflower ethyl ester, soybeans ethyl ester and jatropha methyl ester as reported by Rao et al. (2008), Ramesh et al. (2002) and Rahman et al. (2010) were given as $0.86,0.92$ and 0.88 , respectively. The soybeans ethyl ester value seems closer to the specific gravity of sand apple ethyl ester. At $40^{\circ} \mathrm{C}$ reference temperature, SASO viscosity as shown in Table 1 was $4.2 \mathrm{~mm}^{2} / \mathrm{s}$, this value was slightly lower than that of loofah $\left(6.2 \mathrm{~mm}^{2} / \mathrm{s}\right)$ but higher than groundnut oil of 3.9 $\mathrm{mm}^{2} / \mathrm{s}$ (Bamgboye and Onyia 2012). The kinematic viscosity of SASO determined and ASTM D6751, (2018) oil were 4.2 and $6 \mathrm{~mm}^{2} / \mathrm{s}$ which is much higher than that of refined diesel $\left(3.13 \mathrm{~mm}^{2} / \mathrm{s}\right)$. The higher kinematic viscosity of SASO could be because SASO has higher molecular weight of triglyceride molecules. The pre-heating and transesterification process would significantly reduce the viscosity as reported by Oniya and Bamgboye (2014). The lower kinematic viscosity of SASO means that it exhibits a lower tendency of internal resistance to free motion and therefore less restricting tendency to flow. While making inferences with results of other studies conducted earlier, it was observed that the kinematic viscosity for AGO was
$2.95 \mathrm{~mm}^{2} / \mathrm{s}$ is much lower than that of SASO. However the mean viscosity of SASO fell within the ASTM D6751, (2002) standard of $1.9-6.0 \mathrm{~mm}^{2} / \mathrm{s}$. The value obtained was lower than that of peanut ethyl ester, soybean ethyl ester; palm oil ethyl ester and sunflower ethyl ester were $4.9,4.5,5.7$ and $4.6 \mathrm{~mm}^{2} / \mathrm{s}$ respectively as earlier determined by Ramadhas et al., (2004). This results mean SASO a lower tendency of internal resistance to free motion than these fuels and thus becoming a better fuel in winter and other colder environments. The cloud and pour points obtained for sand apple oil are 4.68 and $3.09^{\circ} \mathrm{C}$, respectively. This is the temperature at which a fuel begins to form wax crystals. These values were lower than that of jatropha curcas of 4.00 and $8.00^{\circ} \mathrm{C}$ as reported by Rao et al. (2008). The two seeds oil values indicated that the cold flow behaviour were fair when compared with $6.00^{\circ} \mathrm{C}$ for diesel fuel (Bamgboye and Oniya, 2012). The lower the cloud point of SASO obtained indicates that the fuel is suitable in temperate environment because weather could be colder before crystals start to form. These crystals very easily clog up filters. Cloud point is directly attributed to the saturated methyl ester content because saturated fats solidify faster than unsaturated fats. Similarly, the lower pour point indicates better the fuel for the same reasons seen in the cloud point. The results shows that the SASO would require as low as $3.09{ }^{\circ} \mathrm{C}$ before it could starts losing its ability to flow. The results also means the lower cloud and pour points of SASO may not require treatment before use in diesel engines during the cold weather as reported by Onyia (2010).

The flash point of SASO was $103^{\circ} \mathrm{C}$ which fell within ASTM D93 (2018) oil $\left(99-169^{\circ} \mathrm{C}\right)$. According to Abdul Rohman et al., (2015), flash point of a volatile liquid is the lowest temperature where the fluid evaporates to form a combustible concentration of gas. This result, therefore, indicates how easy SASO may burn. SASO thus gives off sufficient vapours which can be mixed with air and will ignite momentarily Fuel with higher flash points are less flammable or hazardous, making the fuel safer to handle and transport. The results obtained, therefore, showed that the SASO oil is safer in terms of handling and storage and less hazardous. The heating value for SASO was $42.61 \mathrm{MJ} / \mathrm{kg}$, slightly lower than that of diesel oil of $44.8 \mathrm{MJ} / \mathrm{kg}$. Lower heat of combustion from fuel obtained from SASO means that less energy is released for combustion. It is, thus, a less efficient fuel source than that of diesel oil that exhibits relatively a higher heat of combustion. This indicates that AGO has ability to produce heat of combustion than SASO. Similarly, the lower value of heating value of SASO showed that the carbon contents of SASO have 
considerably reduced during the transesterification reaction.

Conclusion: Fuel properties of SASO and its blends with AGO using eggshell as catalyst was characterized based on America Society for Testing and Material (ASTM D6751) to determine its properties. The results also showed that the SASO is safer in handling and storage and less hazardous. Sand apple ethyl ester - AGO blends was thus observed to have significant effect on nearly all the fuel properties except pour point. The study, therefore, established that the biodiesel obtained from SASO could suitably be blended and used to run compression ignition engines.

\section{REFERENCES}

Abdul, R., Liling, T., Sugeng, R. and Lisa, A (2015). Rapid determination of saponification value in red fruit oil. J. Medicinal Plants. 9(8): 442 - 448.

American Society for Testing and Material (ASTM D6751). (2002). Standard test method for kinematic viscosity and flash point. Article of renewable energy

American Society for Testing and Material (ASTM D97) (2005). Standard test methods for pour point of petroleum product approved by department of defense 12:2928-2959.

American Society for Testing and Material (ASTM D445/446) (2017). Standard test method for kinematic viscosity of transparent and opaque liquids. Book of Standards 1: 350-362.

American Society for Testing and Material (ASTM D5291). (2018). Standard test method for determination of carbon content and hydrogen 3265-3274.

American Society for Testing and Material (ASTM D6751). (2018). Standard specification for biodiesel fuel blend stock for middle distilled fuels 3421-3442

Bamgboye, A. I and Oniya, O. O. (2012). Fuel properties of loofah (Luffa cylindrical L.) biofuel blended with diesel. Afr. J. Environ. Sci. Tech. 6(9): 346-352.

Barnwal, B. K. and Sharma, M. P. (2005). Prospect of biodiesel production from vegetable oil in India. J. Renewable. Sustainable Energy. 9(4): 364-378
Gerpen, J. V. (2005). Biodiesel processing and production. J. Fuel Processing Tech. 86: 1097 1107.

International Organization for Standardization (ISO 3761) 2005. International Organization for Standardization to specify certain characteristic of oil of Rise wood, brazila type Aniba Parviflora.

Odetoye, T. E., Ogunniyi, D. S and Olatunji, GA (2014). Refining and characterization of underutilized seed oil of Parinari polyandra Benth for industrial utilization. Nigerian J. Polymer Appli.Sci. 27: 2538-2551.

Oniya, O. O. (2010). Production of Biodiesel from Loofah and Groundnut oil. Phd Thesis, Department of Agricultural and Environmental Engineering, University of Ibadan Nigeria. 1176.

Oyelade, J. O, Idowu, D. O, Oniya, O. O and Ogunkunle, O. (2017). Optimization of biodiesel Production from sandbox (Hura crepitans L.) seed oil using two different catalysts. Article of Energy sources, Part A: Recovery, Utilization. Environ. Effects. 10:1-10

Organization of the Petroleum Exporting Countries. World Oil Outlook. (OPEC), Vienna. 2009.

Rahman, K. M., Mashud, M., Roknuzzaman, M. and Al-Galib, A. (2010). Biodiesel from Jatropha oil as an alternative fuel for diesel engine. Inter. J. Mech. Mechatronics 10: 1-5.

Ramadhas, A.S. Jayaraj, S. and Muraleedharan, C. (2005). Performance and emission evaluation of a diesel engine fuelled with methyl esters of rubber seed oil. Renewable Energy J. 30:1789-1800.

Ramesh, D. Samptatraja, A. and Venkacha, P. (2002). Production of biodiesel using pilot biodiesel plant with Jatropha. Agricultural engineering College and Research Institute, Rami Nadu Agricultural University. 32: 1-6

Rao, YV. Voleti, R. S. Hariharan, V. S. and Raju, A. V. S. (2008). Jatropha oil methyl ester and its blends used as an alternative fuel in diesel engine. Inter. J. Agric. Biol. Engineer. 1: 2-10. 